\title{
Reversal of maladaptive fibrosis and compromised ventricular function in the pressure overloaded heart by a caveolin-1 surrogate peptide
}

\author{
Dorea Pleasant-Jenkins ${ }^{1,3}$, Charles Reese ${ }^{2,3}$, Panneerselvem Chinnakkannu' ${ }^{1}$, Harinath Kasiganesan', Elena Tourkina², \\ Stanley Hoffman ${ }^{2}$ and Dhandapani Kuppuswamy ${ }^{1}$
}

Chronic ventricular pressure overload (PO) results in congestive heart failure (CHF) in which myocardial fibrosis develops in concert with ventricular dysfunction. Caveolin-1 is important in fibrosis in various tissues due to its decreased expression in fibroblasts and monocytes. The profibrotic effects of low caveolin-1 can be blocked with the caveolin-1 scaffolding domain peptide (CSD, a caveolin-1 surrogate) using both mouse models and human cells. We have studied the beneficial effects of CSD on mice in which PO was induced by trans-aortic constriction (TAC). Beneficial effects observed in TAC mice receiving CSD injections daily included: improved ventricular function (increased ejection fraction, stroke volume, and cardiac output; reduced wall thickness); decreased collagen I, collagen chaperone HSP47, fibronectin, and CTGF levels; decreased activation of non-receptor tyrosine kinases Pyk2 and Src; and decreased activation of eNOS. To determine the source of cells that contribute to fibrosis in CHF, flow cytometric studies were performed that suggested that myofibroblasts in the heart are in large part bone marrow-derived. Two CD45+ cell populations were observed. One (Zone 1) contained CD45+/HSP47 - /macrophage marker+ cells (macrophages). The second (Zone 2) contained CD45 moderate/HSP47+/macrophage marker - cells often defined as fibrocytes. TAC increased the number of cells in Zones 1 and 2 and the level of HSP47 in Zone 2. These studies are a first step in elucidating the mechanism of action of CSD in heart fibrosis and promoting the development of CSD as a novel treatment to reduce fibrosis and improve ventricular function in CHF patients.

Laboratory Investigation (2017) 97, 370-382; doi:10.1038/labinvest.2016.153; published online 23 January 2017

Cardiac hypertrophy begins as an adaptive (compensatory) mechanism in response to pathological or physiological stimulation to decrease ventricular wall stress and maintain cardiac function. For example, when a pathological stimulation such as pressure overload (PO) persists for an extended period of time (as in individuals with hypertension or aortic stenosis), the heart is no longer able to accommodate the increased workload and proceeds into decompensatory processes that lead to congestive heart failure (CHF). One key feature of pathological hypertrophy is fibrosis, the overaccumulation of extracellular matrix (ECM) proteins, particularly collagen $\mathrm{I}$, due to the enhanced expression and decreased degradation of these proteins, resulting in cardiac scarring and impaired ventricular function.
The source of cells that overexpress collagen I and other ECM proteins in the fibrotic heart and other tissues is controversial. The major issue is whether under pathological conditions resident fibroblasts become activated into myofibroblasts, or whether the pathological conditions cause the transdifferentiation into myofibroblasts of exogenous cells (eg, from the bone marrow (BM)) that are recruited into the heart or of local cells (eg, endothelial cells). Some studies support the concept that resident cardiac fibroblasts (originally of epicardial and endothelial origin) are the main cell type involved in the overexpression of collagen I in fibrosis. ${ }^{1-3}$ However, other studies support the concept that in response to cardiac stress (eg, hypertension, ischemia-reperfusion injury, myocardial infarction (MI), PO, Angiotensin II infusion), circulating $\mathrm{BM}$-derived cells migrate into the

1Division of Cardiology, Department of Medicine, Gazes Cardiac Research Institute, Charleston, SC, USA and ${ }^{2}$ Division of Rheumatology, Department of Medicine, Medical University of South Carolina, Charleston, SC, USA

Correspondence: Dr Dhandapani Kuppuswamy, PhD, Division of Cardiology, Gazes Cardiac Research Institute, 114 Doughty Street, Charleston, SC 29425-2221, USA.

E-mail: kuppusd@musc.edu

${ }^{3}$ These authors contributed equally to this work.

Received 28 September 2016; revised 21 November 2016; accepted 1 December 2016 
stressed heart and differentiate into myofibroblasts. ${ }^{4-11}$ It is also noteworthy that the number of circulating putative $\mathrm{CD} 45+/$ collagen I+ myofibroblast precursors (referred to as fibrocytes) is extremely high in human patients with hypertensive heart disease. ${ }^{12}$

Besides being a structural protein involved in the formation and function of plasma membrane caveolae, caveolin-1 is present on cytoplasmic membranes and regulates the function of multiple signaling mechanisms including the MAP kinase family, the protein kinase $\mathrm{C}$ family, $\mathrm{G}$ proteins, growth factor receptor tyrosine kinases, non-receptor tyrosine kinases (NTKs), Akt and eNOS activation, and TGF $\beta$-induced signaling. ${ }^{13-20}$ Caveolin-1 is present at high levels in fibroblasts, adipocytes, endothelial cells, and epithelial cells. It is present at relatively low levels in monocytes and other leukocytes, yet still is functionally important.

Caveolin-1 has been shown to be involved in fibrosis in multiple organs. Lung, skin, and cardiac fibrosis are observed in caveolin-1 KO mice. ${ }^{21-24}$ In lung fibrosis, caveolin-1 is underexpressed in fibroblasts and monocytes in humans (scleroderma (SSc) patients) and mice (treated with bleomycin). ${ }^{13,24-28}$ This deficiency leads to the overexpression of collagen by fibroblasts, the hypermigration of monocytes toward several chemokines due to enhanced chemokine receptor expression, and to the enhanced differentiation of monocytes into myofibroblasts. . $^{13,25,27,29,30}$ Similarly, in heart fibrosis induced by cryoinjury or MI or associated with atrial fibrillation, caveolin-1 expression is low in certain cell types and is associated with ECM accumulation and impaired cardiac function. ${ }^{31-33}$

The effects of caveolin-1 deficiency both in cells and in animals can be reversed either by using virus encoding fulllength caveolin-1 (ref. 14) or using the caveolin-1 scaffolding domain peptide (CSD, amino acids 82-101 of caveolin-1). CSD enters cells ${ }^{34,35}$ and acts as a surrogate for full-length caveolin-1 by inhibiting kinases. ${ }^{20,36}$ CSD inhibits all of the profibrotic cellular functions associated with low caveolin-1 (collagen overexpression by myofibroblasts, monocyte hypermigration, monocyte differentiation into myofibroblasts) as well as inhibiting tissue fibrosis in mouse skin and lung $^{25,27,29,30,37,38}$ and heart, ${ }^{31,32}$ where CSD reduced the number of M2 macrophages in an MI model and decreased collagen accumulation in a cryoinjury model. However, no previous studies have focused on the potential beneficial effect of CSD in a PO model for CHF.

Here we have evaluated the ability of CSD to inhibit the progression of fibrosis and heart failure in a mouse model in which PO is caused by transverse aortic constriction (TAC). CSD had remarkably beneficial effects on fibrosis (expression of collagen I and the collagen chaperone HSP47) and heart function determined by echocardiography. While CSD has previously been shown to reduce the number of M2 macrophages in a MI model ${ }^{32}$ and to decrease collagen accumulation in a cryoinjury model, ${ }^{31}$ here we have made the novel observations that: (1) CSD inhibits myocardial fibrosis in a PO model, (2) CSD has a beneficial effect on ventricular function in this model, (3) CSD reverses PO-induced NTK and eNOS activation in vivo, and (4) HSP47 (which is a surrogate marker for cells that express collagen $\mathrm{I}^{32}$ ) levels are greatly increased in the PO myocardium, reversed by CSD, and is localized in cells expressing CD45, suggesting that these myofibroblasts are of bone marrow origin.

\section{MATERIALS AND METHODS \\ Animals}

Male, 10-12-week-old wild-type C57BL/6 J mice were purchased from Jackson Laboratory (Bar Harbor, Maine, USA). All procedures were performed under a protocol approved by the Medical University of South Carolina (MUSC) Institutional Animal Care and Use Committee.

\section{Transverse Aortic Constriction}

Left Ventricular (LV) PO was induced by tying a suture around the transverse aorta over a 27 -gauge blunted needle causing occlusion of the aorta and a stenotic lumen. The needle was withdrawn. Control mice underwent Sham surgery. Mice were killed by cervical dislocation under deep isoflurane anesthesia. Hearts were removed for biochemical studies or fixed with formalin for histochemistry and immunohistochemistry (IHC).

\section{Echocardiography (Echo)}

Echocardiography was performed at baseline (before sham or transverse aortic constriction (TAC) surgery), and at various times after surgery depending on experimental protocol (see below). Echocardiography was conducted using the Vevo2100 imaging system (VisualSonics, Toronto, ON, Canada). The 22-55 MHz linear transducer probe (MS550D) was used for two-dimensional B-mode and $\mathrm{M}$-mode analyses. Heart rate was maintained at 400-550 bpm via isoflurane anesthesia. End-diastolic LV dimensions and posterior wall thickness were measured according to the American Society of Echocardiography guidelines as applied to mice. LV wall thickness was measured at the level of the intraventricular septum and the posterior wall. Offline analyses of M-mode images of the parasternal short-axis view at papillary level were performed using VisualSonics Vevo2100 1.2.0 software to calculate ejection fraction (EF), end-diastolic volume (EDV), and posterior wall thickness (WTh). B-mode images of the parasternal long-axis were used to calculate cardiac output (CO), stroke volume (SV), EF, and EDV.

\section{CSD Experimental Protocols}

CSD (amino acids 82-101 of caveolin-1, DGIWKAS FTTFTVTKYWFYR- $\mathrm{NH}_{2}$ ), was purchased from Elim. Two separate protocols were used depending on the purpose of the experiment. In the long-term protocol used for LV function studies and IHC, TAC mice were evaluated by Echo at 1 week after surgery. At this point daily CSD or vehicle treatments (i.p. injections of $100 \mu \mathrm{l}$ of CSD $(50 \mu \mathrm{g} / \mathrm{kg} /$ day $)$ or vehicle 
$(1 \%$ DMSO $))$ were initiated in both TAC and Sham animals. Echo measurements were performed in all mice at 4 and $6 \mathrm{wk}$. Animals were killed at 4 and 6 week. In a second short-term protocol used for flow cytometry experiments and RT-PCR studies, daily CSD and vehicle treatments were initiated the day of surgery. Mice were killed at 2 weeks. Samples for western blotting were obtained from both protocols.

\section{Western Blotting}

Experiments were performed as previously described ${ }^{39}$ with minor modifications. Soluble and insoluble fractions of left ventricle (LV) were prepared. Briefly, LV (50 mg wet weight) were isolated and homogenized using a T25 Ultra-Turrax homogenizer for $1 \mathrm{~min}$ on ice in $1 \mathrm{ml}$ of radioimmunoprecipitation assay (RIPA) buffer $(50 \mathrm{mM}$ Tris- $\mathrm{HCl}(\mathrm{pH} 7.4)$, $1 \%$ NP-40, $0.25 \%$ sodium deoxycholate, $150 \mathrm{mM} \mathrm{NaCl}, 0.1 \%$ sodium dodecyl sulfate and protease and phosphatase inhibitors). The homogenate was kept on ice for $15 \mathrm{~min}$, then centrifuged at $10000 \mathrm{~g}$ for $15 \mathrm{~min}$. The soluble fraction was mixed with an equal volume of $2 \times$ Sample Buffer and boiled; the insoluble pellet fraction was suspended in $0.5 \mathrm{ml}$ $1 \times$ Sample Buffer and boiled, then reclarified. Samples were resolved by SDS-PAGE at $4{ }^{\circ} \mathrm{C}$ (Invitrogen $4-12 \%$ Bis-Tris Gels, $1 \times$ MOPS buffer) and transferred to Invitrolon PVDF membranes (ThermoFisher Scientific (Invitrogen), Waltham, MA, USA). Membranes were blocked, incubated with primary antibodies (Table 1), washed, incubated with HRPlabeled secondary antibodies, and detected by enhanced chemiluminescence.

\section{RT-PCR}

For quantitative assessment of relative mRNA levels, total RNA was isolated from the LV tissue samples using RNeasy mini kits (Qiagen, Santa Clarita, CA, USA). cDNA was synthesized using $0.5 \mu \mathrm{g}$ total RNA using iScript cDNA synthesis kit (Bio-Rad Laboratories, Hercules, CA, USA) containing iScript reaction mixture and iScript reverse transcriptase. The entire reaction was cycled for $5 \mathrm{~min}$ at $25^{\circ} \mathrm{C}, 30 \mathrm{~min}$ at $42^{\circ} \mathrm{C}$, and $5 \mathrm{~min}$ at $85^{\circ} \mathrm{C}$. RT-PCR was performed using SsoAdvanced Universal SYBR Green Super Mix Kit (Bio-Rad Laboratories, Hercules, CA, USA) and analyzed using iCycler iQ real-time PCR detection system (Bio-Rad Laboratories). Validated PrimePCR primers (BioRad Laboratories) were purchased for the following genes; Collagen I, Fibronectin, HSP47, CTGF (connective tissue growth factor, CCN2), and GAPDH. The thermal cycling parameters were: Polymerase activation, $30 \mathrm{~s}$ at $95^{\circ} \mathrm{C}$; denaturation, 40 cycles at $95^{\circ} \mathrm{C}$ for $10 \mathrm{~s}$ each; and annealing, $60{ }^{\circ} \mathrm{C}$ for 30 seconds. GAPDH was used as an internal control for normalizing target gene expression levels as described. ${ }^{40}$

\section{Histochemistry and IHC}

Mouse hearts were fixed with formalin for $12-18 \mathrm{~h}$, dehydrated with several ethanol and xylene washes, and embedded in paraffin. Tissue sections $(0.7 \mu \mathrm{m}$ thick) were stained with Picrosirius Red to detect collagen deposition. To detect HSP47, paraffin-embedded tissue sections were heated in an oven at $60^{\circ} \mathrm{C}$ for $1 \mathrm{~h}$ before deparaffinization and rehydration into water. Antigen retrieval was performed using Citrate Buffer (10 mM Citric Acid, 0.05\% Tween 20, pH 6) at $90-100^{\circ} \mathrm{C}$ in a water bath for $20 \mathrm{~min}$. After cooling, slides were washed in water followed by $1 \times$ PBS and blocked with $10 \%$ Normal Donkey Serum in PBS for $1 \mathrm{~h}$ at room temperature (RT) in a humid chamber. Directly labeled anti-HSP47 (Table 1) at a final $2 \mu \mathrm{g} / \mathrm{ml}$ was incubated with slides in humid conditions at RT for $5 \mathrm{~h}$. Slides were then washed with $1 \times$ PBS and stained with the nuclear stain DAPI at RT for $30 \mathrm{~min}$.

\section{Cell Isolation/Flow Cytometry}

Total heart cells were isolated as previously described with minor modifications. ${ }^{41}$ Briefly, mice were anesthetized using isoflurane (5\% in 100\% oxygen in induction chamber) and treated with heparin (200 IU, i.p. injection). Anesthesia was maintained using nose cones. The thoracic region was cleaned using sterile gauze. A bilateral thoracotomy was performed and the heart and greater vessels removed and perfused at constant pressure $(70 \mathrm{mmHg})$ at $37^{\circ} \mathrm{C}$ for 5 min with buffer

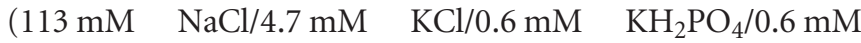
$\mathrm{NaHPO}_{4} / 1.2 \mathrm{mM} \quad \mathrm{Mg}_{2} \mathrm{SO}_{4} / 0.032 \mathrm{mM}$ phenol red/12 mM $\mathrm{NaHCO}_{3} / 10 \mathrm{mM} \mathrm{KHCO}_{3} / 10 \mathrm{mM}$ HEPES/30 mM taurine/ $10 \mathrm{mM}$ 2,3-butanedione monoxime (BDM)/5.5 mM glucose ( $\mathrm{pH}$ 7.4). The tissue was then perfused with the same buffer containing Liberase blendzyme (Roche) $(0.25 \mathrm{mg} / \mathrm{ml}) /$ trypsin $(0.14 \mathrm{mg} / \mathrm{ml}) / \mathrm{CaCl}_{2}(12.5 \mu \mathrm{M})$. The heart was removed from the cannula when it became palpably flaccid due to the effect of the enzymes. The LV including the septum was dissected, minced, and gently agitated for $5 \mathrm{~min}$ to disperse cells into fresh buffer containing 5\% fetal bovine serum to block further digestion.

For flow cytometry, isolated cells were collected by centrifugation at 1200 r.p.m. for $10 \mathrm{~min}$ at $4{ }^{\circ} \mathrm{C}$, resuspended in $1 \mathrm{ml}$ of Cytofix/Cytoperm (554722, BD Biosciences), and incubated for $20 \mathrm{~min}$ at $4{ }^{\circ} \mathrm{C}$ to fix and permeabilize the cells before immunolabeling. Cells were then washed in FACS buffer (BD Perm/Wash Buffer, Product \#554723, BD Biosciences) and resuspended in FACS buffer/Fc Block ( $1 \mu \mathrm{g}$ per $1 \times 10^{6}$ cells, Product \#564220, BD Biosciences) for $30 \mathrm{~min}$ at $4^{\circ} \mathrm{C}$. Samples were labeled with the antibodies summarized in Table 1 . All incubations with antibody were $30 \mathrm{~min}$ at $4{ }^{\circ} \mathrm{C}$ in FACS buffer on a rocker at low speed. All washes and resuspensions were done with FACS buffer. Immunolabeled cells were analyzed on a Guava Easycyte 8HT (Millipore, Norwood, OH, USA). At least 20000 events were recorded per sample.

\section{Statistical Analyses}

Values are presented as mean \pm s.e.m. Differences were analyzed between groups using one-way analysis of variance 
Table 1 Antibodies used in experiments

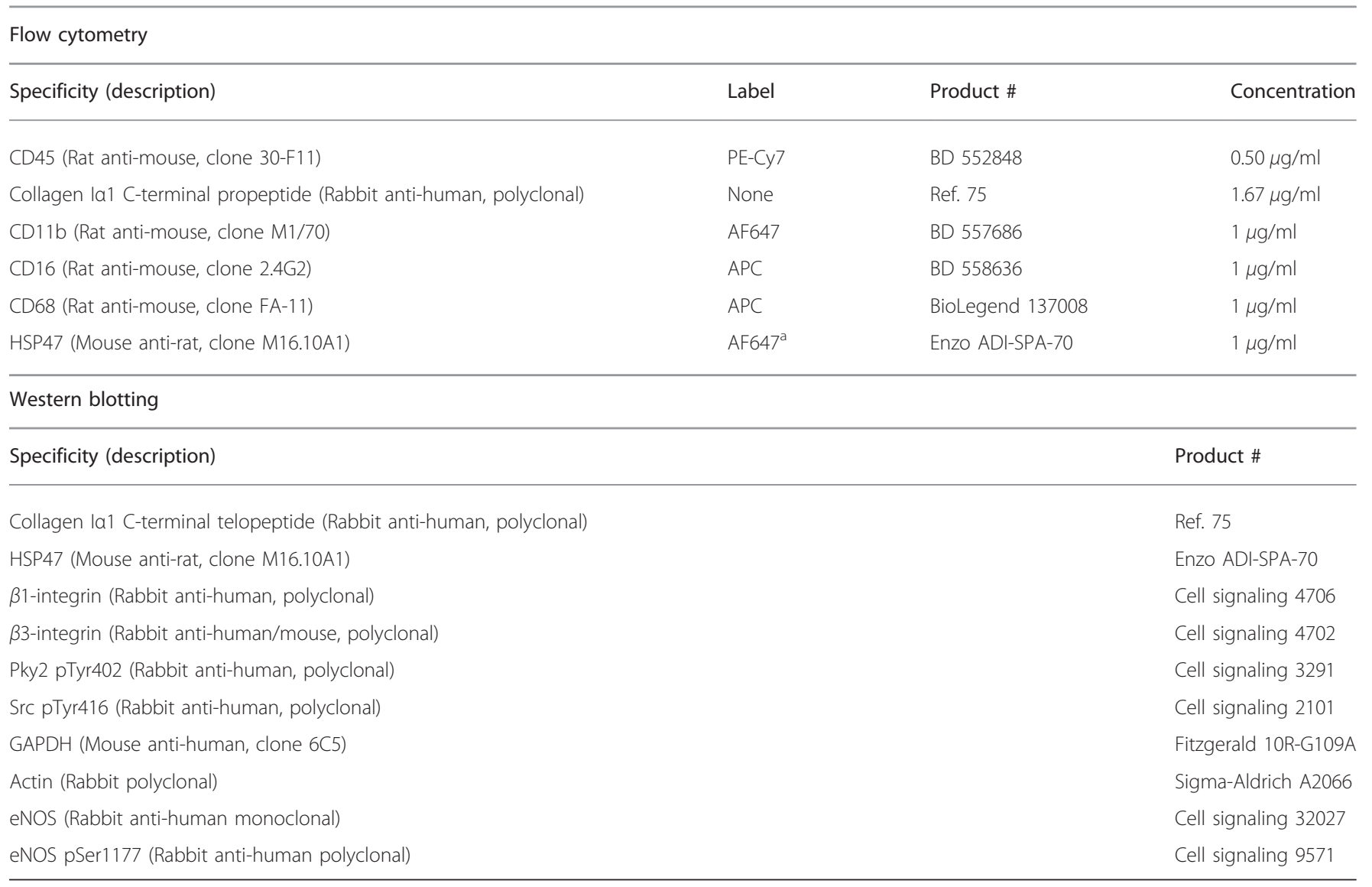

Abbreviation: AF, Alexa Fluor.

aLabeled using an Alexa Fluor 647 Protein Labeling Kit (Invitrogen, Carlsbad, CA, A-20173) as described by the manufacturer.

(ANOVA) followed by a post hoc Tukey's multiple comparison to determine statistical significance.

\section{RESULTS}

Decreased levels of caveolin-1 have been linked to fibrosis in several diseases. CSD has been demonstrated to serve as a surrogate for caveolin-1 and thereby to reverse fibrosis in vivo in the lungs ${ }^{29,38}$ and heart both in a cryoinjury model ${ }^{31}$ and a myocardial infarction (MI) model. ${ }^{32}$ In this paper, we focus on a distinct model; PO-induced hypertrophy and cardiac failure.

\section{CSD Inhibits PO-Induced Fibrosis In Vivo}

Fibrosis in TAC-induced PO was determined in terms of the levels of collagen and the collagen chaperone HSP47 (which has frequently been used as a surrogate marker for collagen) in the LV by western blotting, by IHC for HSP47, and by Picrosirius Red Staining for collagen (Figure 1). Western blots showed a 3 -fold increase in collagen and 4 -fold increase in HSP47 levels induced by TAC at all time points tested. This increase was significantly inhibited by CSD with progressively better inhibition as the length of time of CSD treatment increased (Figures 1a and c). IHC for HSP47 showed a 7-fold increase in the number of positive cells in TAC mice treated with vehicle (Figure 1b). CSD decreased staining down to the baseline level observed in Sham mice. Similarly, Picrosirius Red staining showed a 3-fold increase in collagen volume in TAC mice that was decreased to baseline with CSD treatment (Figure 1d).

The effects of TAC and CSD on the expression of proteins associated with fibrosis were further evaluated by RT-PCR (Figure 2). These studies confirmed the results of Western blotting experiments, showing that the expression of collagen I and HSP47 are greatly increased by TAC and that this increase is inhibited by CSD. In addition, RT-PCR studies demonstrated that fibronectin and connective tissue growth factor (CTGF) expressions are increased by TAC and inhibited by CSD.

\section{PO-Induced Maladaptive Changes are Suppressed by CSD}

We evaluated the effects of CSD on PO-induced changes in heart function in terms of $\mathrm{EF}, \mathrm{CO}$, and $\mathrm{SV}$ and geometry in terms of WTh and EDV. Both M-mode (Figure 3) and B-mode 
a
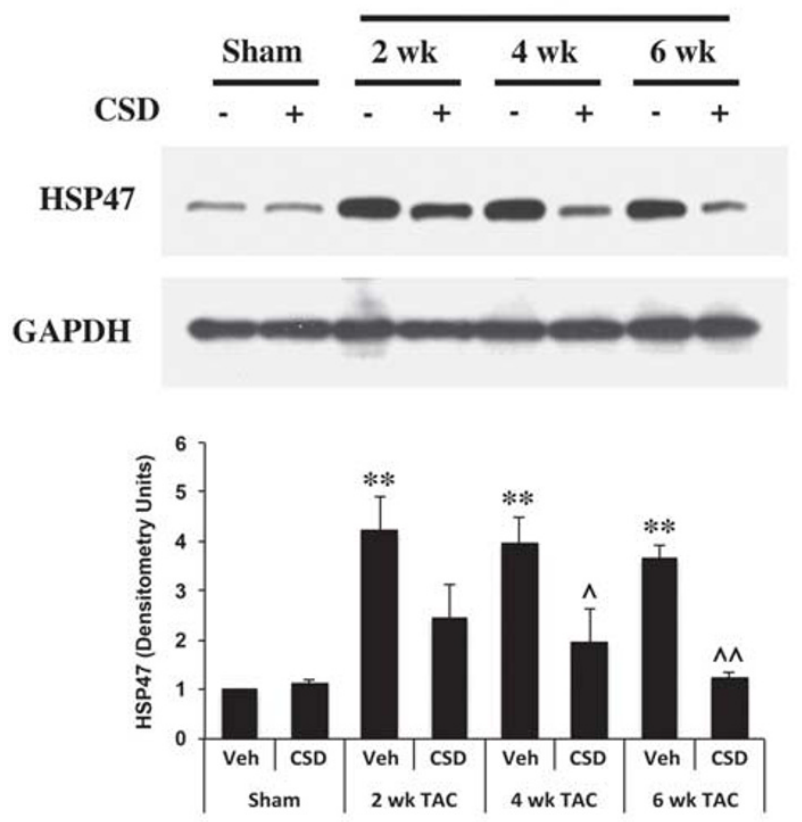

b
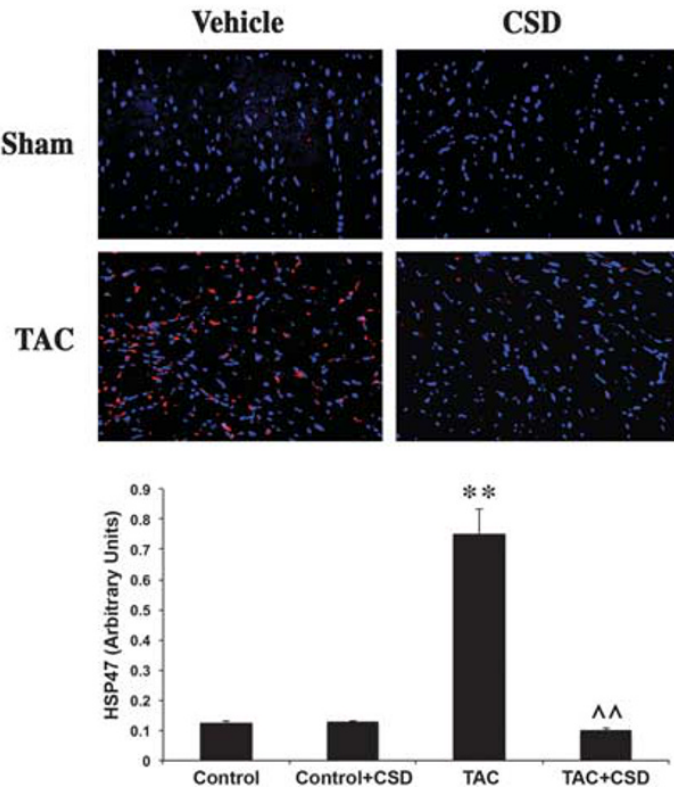

C

TAC

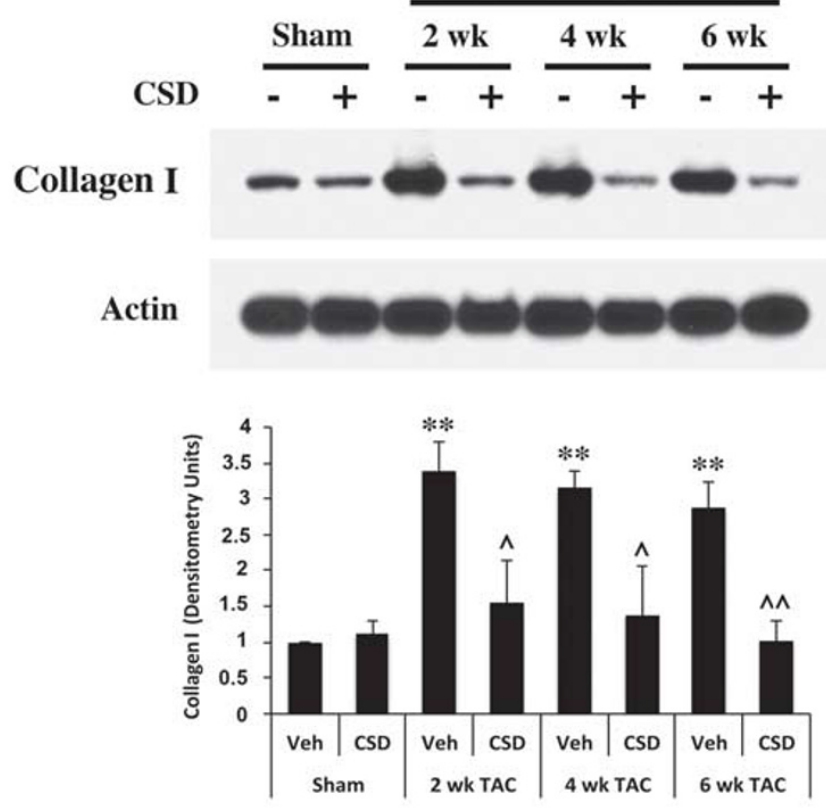

d
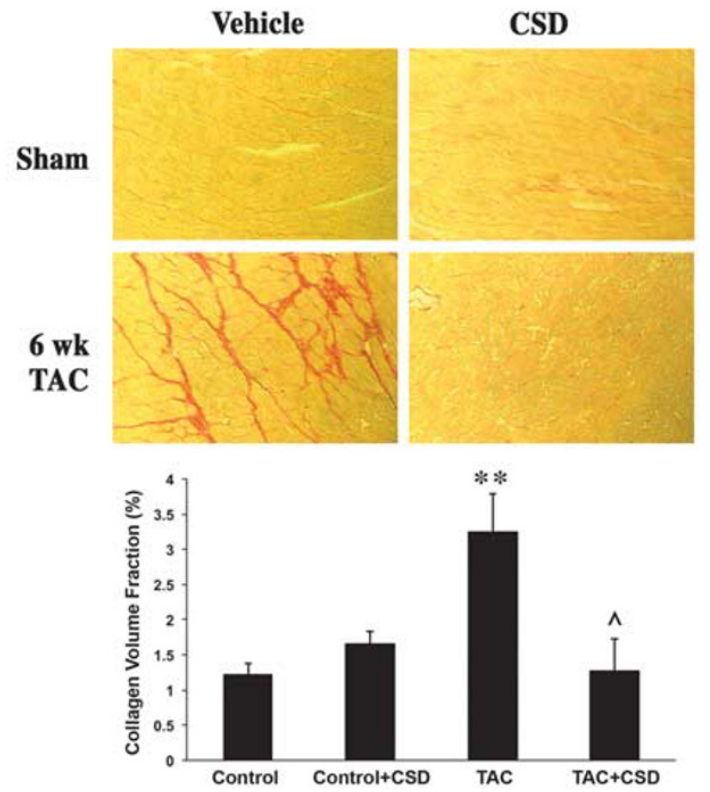

Figure 1 CSD reverses the effect of TAC on HSP47 and Collagen I levels. Mice were treated as described in the Methods. For Sham control, samples from 6 weeks after surgery were used. LV tissue was used for histochemical analyses or extracted with RIPA buffer and the resulting soluble and insoluble fractions used in western blotting experiments. (a) The RIPA soluble protein fractions from mice receiving the indicated treatments were analyzed by Western blotting using antibodies against HSP47 and GAPDH (loading control). (b) LV from the indicated mice (6 weeks after surgery) were stained with anti-HSP47 (red), and co-stained with DAPI (blue) to detect nuclei. The graph quantifies HSP47 staining intensity per field in arbitrary units. Graph data were obtained from 10 fields per slide, three to four mice per category. (c) The RIPA insoluble protein fraction from mice receiving the indicated treatments were Western blotted using antibodies against Collagen I and actin (loading control). (d) LV tissue from the indicated mice harvested 6 weeks after surgery was stained with Picrosirius red. The graph quantifies collagen volume fraction, calculated from photomicrographs using Sigma Scan Pro-5. At least 25 fields per mouse, two mice per category were used. ${ }^{* *} P<0.01$, TAC vs Control; $\wedge P<0.05, T A C+C S D$ vs TAC+Vehicle; $\wedge \wedge P<0.01$, TAC+CSD vs TAC+Vehicle.

(Figure 4) data are presented. M-mode echo measurements of TAC mice treated with vehicle showed a progressive decrease in heart function $(\mathrm{EF})$ over the entire 6 weeks of the experiment as well as pathological changes in geometry (WTh and EDV). In contrast, in CSD-treated TAC mice, a significant improvement was observed in EF and WTh between 4 and 6 weeks.

B-mode echo measurements were used to analyze SV and $\mathrm{CO}$ along with EF and EDV. These measurements also 
a

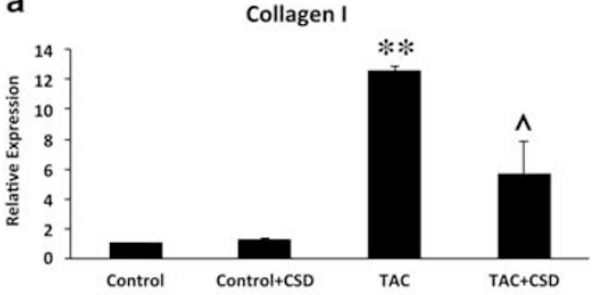

b

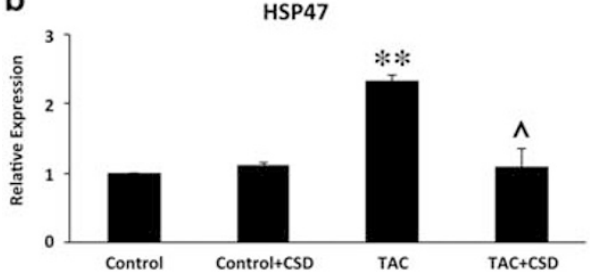

C

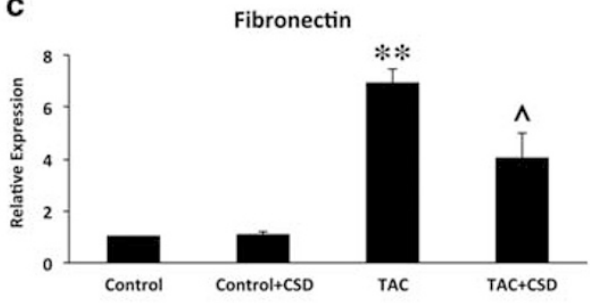

d

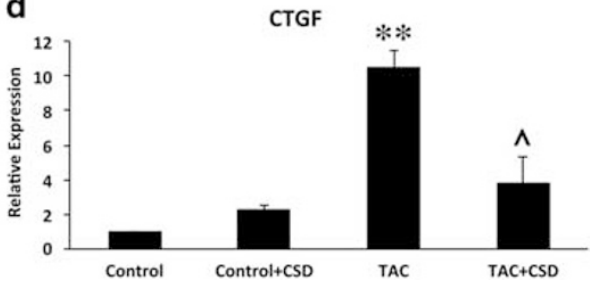

Figure 2 RT-PCR evaluation of effects of TAC and CSD on fibrosis. LV samples from the indicated mice 2 weeks after surgery were used for quantitative RT-PCR analyses of (a) Collagen I, (b) HSP47, (c) fibronectin, and (d) CTGF message levels. GAPDH was used for normalization. The expression level of each gene in vehicle-treated Sham mice was defined as 1 arbitrary unit. At least three mice were used for each group with analyses performed in duplicate. ${ }^{* *} P<0.01$, TAC vs Control; $\wedge P<0.05$, TAC+CSD vs TAC+vehicle.

showed a progressive decrease in heart function $(\mathrm{EF}, \mathrm{SV}$, and $\mathrm{CO}$ ) and an increase in EDV. In CSD-treated TAC mice EF, $\mathrm{SV}$, and CO showed a significant improvement while EDV was not improved. The beneficial effects were particularly striking when the data for individual mice at 6 week were compared for each parameter (Figure 4, right panels). Almost every TAC mouse that received CSD showed an SV and a CO comparable to Sham mice and better than TAC mice that received vehicle $(P<0.001$ for SV and $\mathrm{CO}$ comparing TAC $+\mathrm{CSD}$ to TAC+vehicle). These data suggest that long-term CSD treatment in mice with $\mathrm{PO}$ causes a significant beneficial effect.

\section{CSD Inhibits PO-Induced Changes in Integrin Levels and Activation of Pyk2 and Src}

We recently demonstrated that NTKs regulate cardiac fibrosis in that treatment with a specific NTK inhibitor, dasatinib, suppressed cardiac fibroblast proliferation and ECM deposition (fibronectin assembly). ${ }^{42}$ Moreover, we found that NTK activation is regulated by $\beta 3$-integrin. ${ }^{39}$ To determine whether the antifibrotic effect of CSD also involves the inhibition of changes in integrin levels and NTKs activation, we assessed the levels of $\beta 1$-integrin, $\beta 3$-integrin, phospho-Pyk2-Y402, and phospho-Src-Y416 in LV extracts (Figure 5). Both $\beta 1$ and $\beta 3$-integrin levels were increased 3 -fold as early as 2 weeks after surgery and continued to be elevated throughout the 6week experiment. Moreover, the level of the higher molecular form of $\beta 3$-integrin (shown previously to be the activated form ${ }^{43}$ ) was increased 10-fold. CSD significantly decreased these increases in integrin levels (Figure 5). Analyses of NTK activation reveal that Pyk2 is activated at least 5-fold and c-Src is activated at least 2-fold throughout the time course of the experiment and CSD significantly inhibit NTK activation
(Figure 5). Analyses of total Pyk2 and c-Src levels showed no changes due to PO (not shown). These results mimic those obtained with HSP47 and collagen I (Figure 1).

\section{CSD Inhibits PO-Induced Changes in eNOS}

Caveolin-1 directly interacts with eNOS and blocks its activation. ${ }^{20}$ eNOS activation involves both phosphorylation at multiple sites including serine-1177 (S1177) and homodimerization. Activated eNOS then couples with a ferrousdioxygen complex to generate NO. ${ }^{44,45}$ We observed increased levels of the eNOS homodimer in the TAC heart using an antibody specific for phosphorylated S1177 (Figure 6). Although a total eNOS antibody recognized the monomere, it did not detect dimers suggesting that the level of phosphorylation is higher in eNOS dimers than monomers. In mice treated with CSD, the level of phosphorylated eNOS dimers in TAC hearts was reduced to baseline level. However, the level of monomeric eNOS $(140 \mathrm{kDa})$ detected using either the S1177 antibody or the total eNOS antibody was not affected by TAC or by CSD (Figure 6).

\section{HSP47+ Cells in the PO Myocardium are CD45 moderate}

To determine the origin of the HSP47+ cells that appear in the PO heart (Figure 1), we analyzed total heart cells by flow cytometry using antibodies against HSP47, CD45, and several other markers. In both Sham and TAC hearts, when flow cytometry data was plotted as a scatter plot for CD45 and HSP47 fluorescence, there were three obvious cell populations; CD $45^{\text {high }} / \mathrm{HSP} 47-$, CD $45^{\text {moderate }} / \mathrm{HSP} 47+$, and CD45-/ HSP47 - that we will refer to respectively as Zones 1, 2, and 3 (Figure $7 \mathrm{a}$ ). The \% of cells in Zones 1 and 2 was increased about 2.5 -fold by TAC (Figure $7 \mathrm{~b}$ ). To evaluate whether the moderate level of CD45 positivity in Zone 2 (Near IR-B 

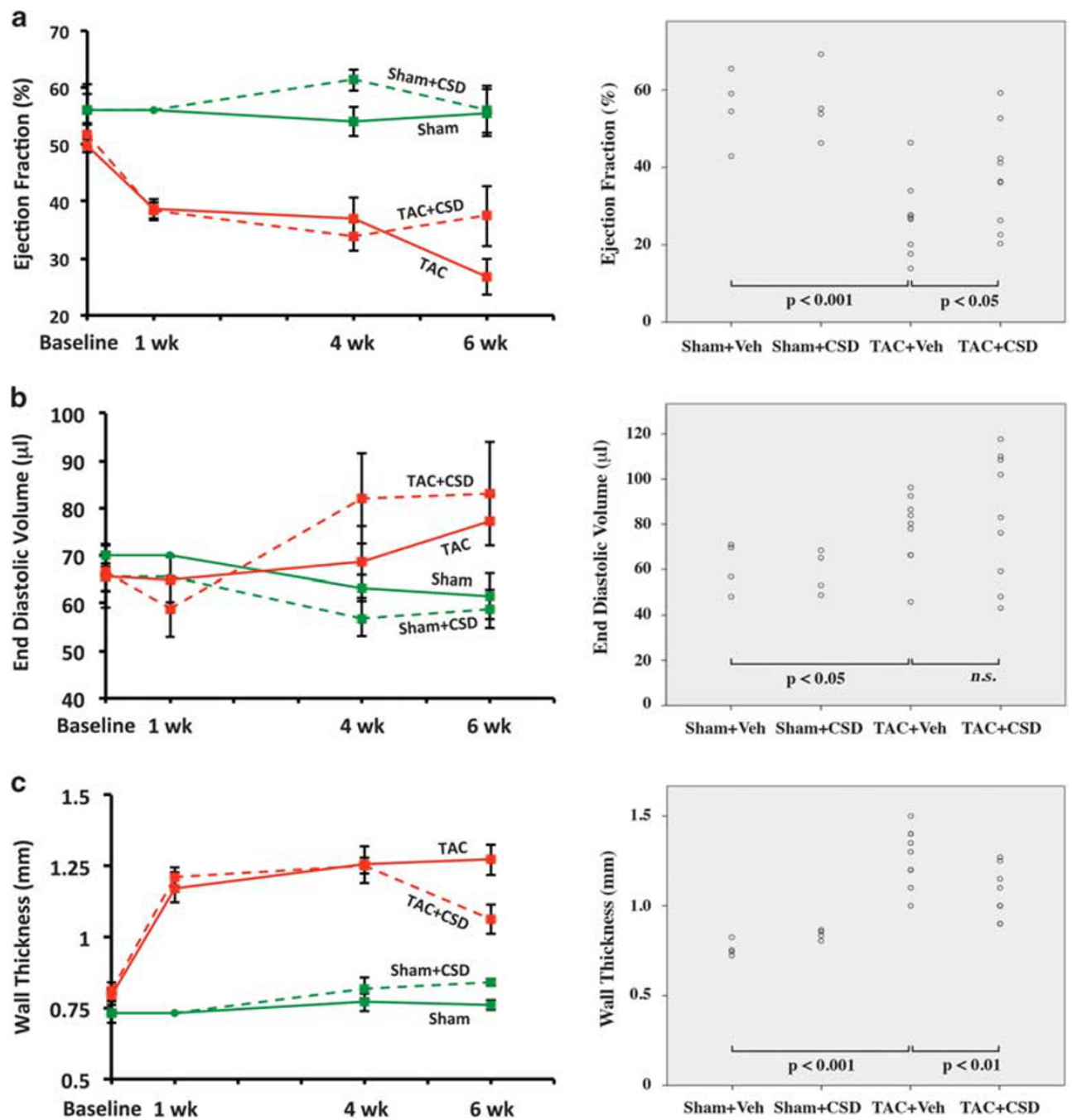

Figure 3 CSD suppresses hypertrophy and improves ventricular function. Baseline 2-D Echo data were collected before Sham or TAC surgery to ensure that all mice were similar. Mice were treated as described in the Methods. M-mode echocardiographic measurements were used to quantify: (a) LV ejection fraction (EF); (b) LV end-diastolic volume (EDV) and (c) LV posterior wall thickness (WTh). Each group contained four mice for Sham and at least nine mice for TAC. Scatter plots on the right of $(\mathbf{a}-\mathbf{c})$ show data for individual mice (one symbol per mouse, four mice per group for Sham mice, nine mice per group for TAC mice) at the 6 week time point. In addition, $P$-values are shown in these scatter plots comparing Sham+Vehicle to TAC+Vehicle and comparing TAC+Vehicle to TAC+CSD.

Channel) could be due to spillover from the HSP47 channel (Red Channel), we performed single label experiments with antibodies labeled with the appropriate fluors. We observed no spillover either from the Near IR-B Channel into the Red Channel or from the Red Channel into the Near IR-B channel (Figure 7c).

To determine whether CD45+ and CD45 $5^{\text {moderate }}$ cells differed in their levels of macrophage markers, we also included antibodies against CD11b, CD16, and CD68 in these experiments. Although HSP47 levels were high in Zone 2 and negligible in Zones 1 and 3; CD11b, CD16, and CD68 levels were high in Zone 1 and negligible in Zones 2 and 3 (Figure 8a). Therefore, the cells in Zone 1 have the characteristics of macrophages, whereas the cells in Zone 2 have the characteristics of fibrocytes. The markers detected on cells in Zone 1, 2, and 3 are summarized in Figure 8b.

\section{DISCUSSION}

Reactive myocardial fibrosis is observed as a common feature in patients with hypertension or aortic stenosis and contributes to maladaptive ventricular remodeling and cardiac dysfunction, including loss of diastolic compliance. ${ }^{46-50}$ Our present work using a mouse TAC model to induce LVPO shows several observations supporting the concept that the CSD peptide (a surrogate for caveolin-1) regulates the progression of TAC-induced heart failure and fibrosis and that CSD can be developed as a treatment for heart failure: (1) TAC mice exhibit compromised ventricular 

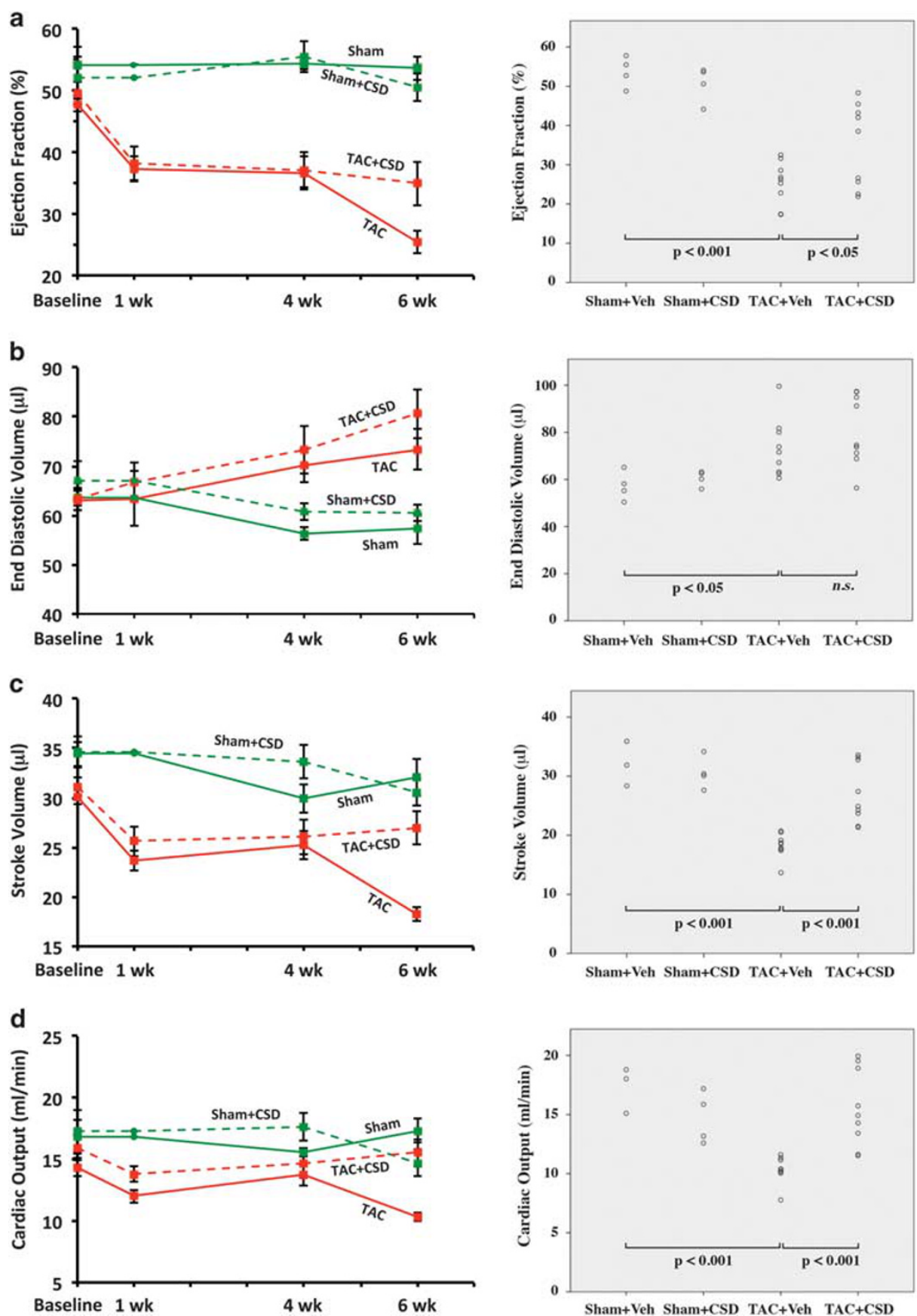

Figure 4 CSD improves ventricular function and cardiac output (CO). Baseline 2-D Echo data were collected before Sham or TAC surgery to ensure that all mice were similar. Mice were treated as described in the Methods. B-mode Echo measurements were used to quantify: (a) LV ejection fraction (EF); (b) end-diastolic volume (EDV); (c) stroke volume (SV), and (d) CO. Scatter plots on the right of (a-d) show EF, EDV, SV and CO data for individual mice (one symbol per mouse, four mice per group for Sham mice, nine mice per group for TAC mice) at the 6 week time point. In addition, $P$-values are shown in these scatter plots comparing Sham+Vehicle to TAC+Vehicle and comparing TAC+Vehicle to TAC+CSD.

function. CSD blocks or reverses these effects on EF (ejection fraction), CO (cardiac output), SV (stroke volume), and posterior wall thickness (WTh). (2) CSD treatment decreases the TAC-induced overexpression of proteins directly involved in fibrosis both at the protein level (collagen I, HSP47) and the mRNA level (collagen I, HSP47, CTGF, fibronectin).
(3) CSD treatment inhibits the expression of integrins $(\beta 1, \beta 3)$ and the activation of NTKs (Pyk2 and Src) involved in the regulation of fibrosis. (4) Flow cytometry studies suggest that the population of cells that express high levels of HSP47 in TAC hearts is BM-derived because these cells are moderately positive for CD45. 
a
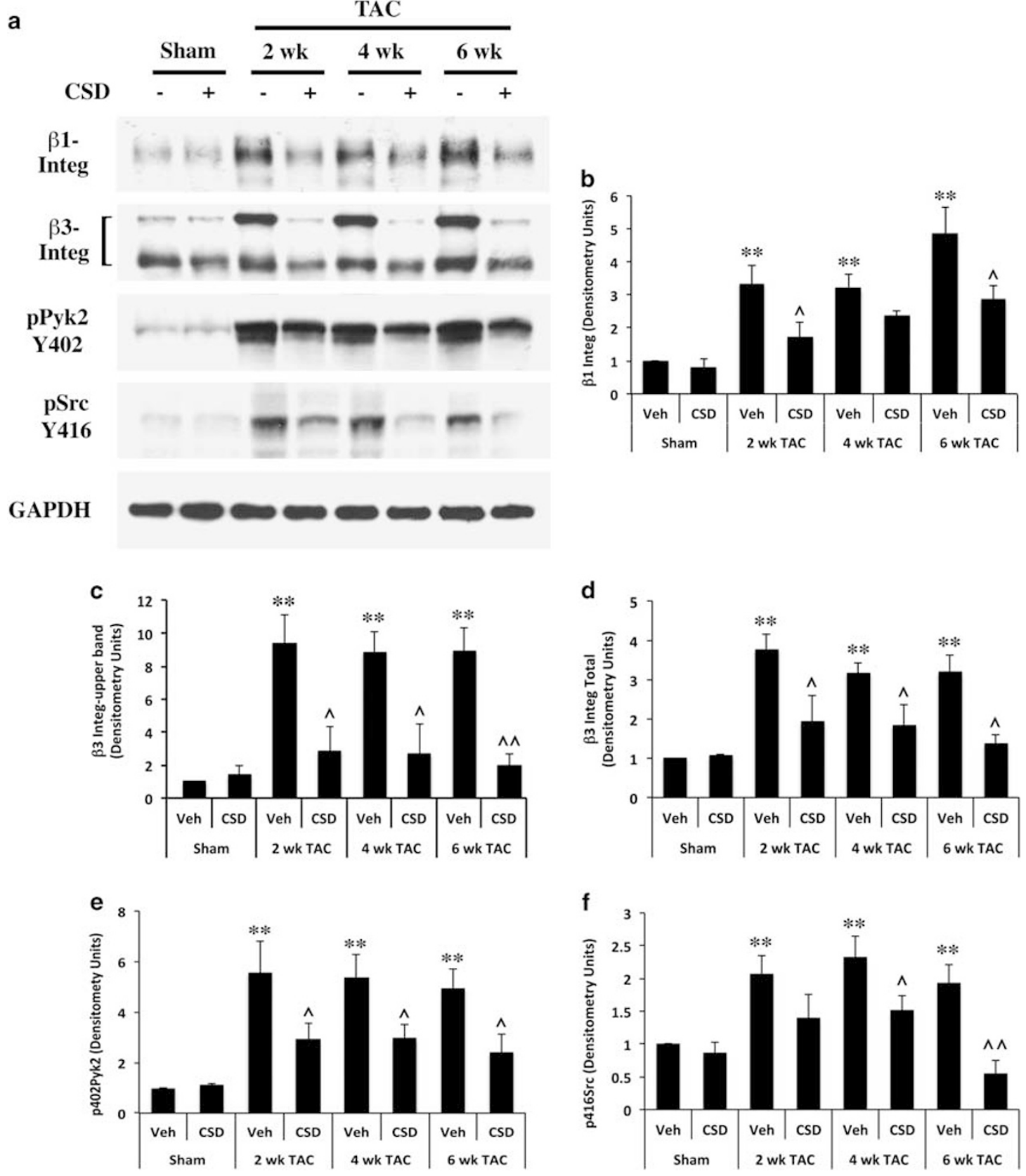

Figure 5 CSD inhibits increases in integrin levels and NTK activation. Mice were treated as described in the 'Materials and Methods' section. For Sham control, samples from 6 weeks after surgery were used. LV tissue was extracted with RIPA buffer and the resulting soluble fraction used in western blotting experiments using antibodies against $\beta 1$-integrin, $\beta 3$-integrin, phospho-Pyk2-Y402, phospho-Src-Y416, and GAPDH (loading control). A representative Western blot is shown in (a). Densitometric quantification of data from three independent experiments is (b) $\beta 1$-integrin, (c) $\beta 3$-integrin upper band, (d) $\beta 3$-integrin both bands, (e) pPyk2, and (f) pSrc. ${ }^{*} P<0.01$, TAC vs Sham; $\wedge P<0.05$, TAC+CSD vs TAC+vehicle, $\wedge \wedge P<0.01$ TAC $+C S D$ vs TAC+vehicle.

The antifibrotic role of caveolin-1 in several organs is well established under various pathological conditions. . $^{13,24-28,51}$ However, only a very few studies have explored caveolin-1 in the heart. Studies performed in caveolin-1 KO mice show that: (1) Caveolin-1 loss can lead to cardiac hypertrophy, fibrosis, and compromised contractile function; $;^{23,52}$ (2) Myocardial cryoinjury in WT mice results in fibrosis mostly around blood vessels, but interstitial areas are also affected in $\mathrm{KO}$ mice; ${ }^{31}$ (3) $\mathrm{MI}$ causes exacerbated cardiac dysfunction and mortality in $\mathrm{KO}$ mice, ${ }^{53}$ and (4) MI causes exacerbated fibrosis by promoting M2 macrophage activation. ${ }^{32}$ Furthermore, caveolin-1 deficiency is linked to cardiac fibrosis in patients with atrial fibrillation. ${ }^{33}$ However, the critical role played by caveolin-1 during PO-induced cardiac fibrosis has not yet been explored. 
We propose three stages at which CSD may be having a beneficial effect: (1) CSD may inhibit the recruitment of BM-derived cells into fibrotic tissue. (2) CSD may inhibit the

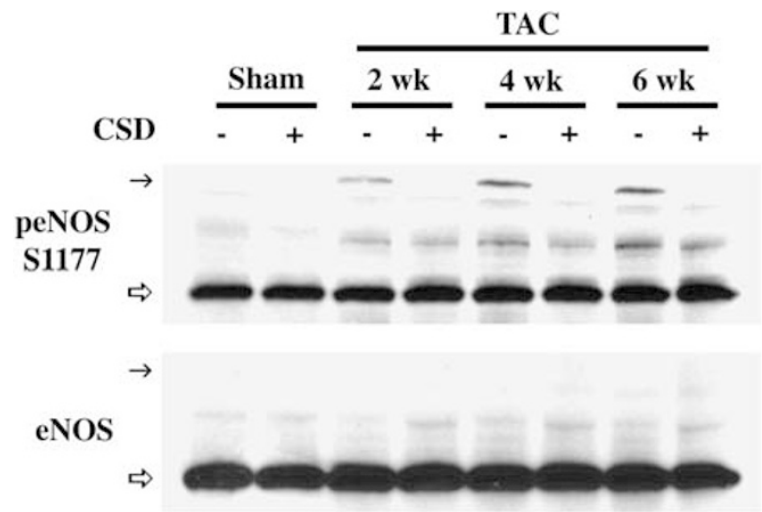

Figure 6 CSD inhibits eNOS activation. Mice were treated as described in the Methods. For Sham control, samples from 6 weeks after surgery were used. LV tissue was extracted with RIPA buffer and the resulting soluble fraction used in Western blotting experiments using antibodies against phospho-eNOS-S1177 and total eNOS. Thin arrow indicates the position of dimeric eNOS (280 kDa), open arrow indicates monomeric eNOS $(140 \mathrm{kDa})$. Similar results were obtained in independent experiments. differentiation of monocytes into fibrocytes/myofibroblasts. These possibilities are supported by our previous studies indicating that caveolin-1 regulates monocyte migration and differentiation into fibrocytes/myofibroblasts via a mechanism involving TGF $\beta$ receptors, Smad 2/3, Src, Lyn, MEK, and ERK. ${ }^{25,30,37}$ (3) CSD may inhibit collagen I expression by fibroblasts. We and others previously showed that caveolin-1 regulates collagen I production in lung fibroblasts via mechanisms involving $\mathrm{PKC} \varepsilon, \mathrm{PKC} \alpha$, MEK, ERK, JNK, Smad 2/3, and Akt. ${ }^{13,14,24,38}$ Moreover, in studies on cardiac fibroblasts, we have previously shown that collagen I expression is regulated by a signaling mechanism involving $\beta 1$ and $\beta 3$ integrins and the non-receptor tyrosine kinases (NTKs) Src and Pyk2. ${ }^{39,42,43}$ Similar to our previous findings, both $\beta 1$ and $\beta 3$ integrins showed increased expression in PO myocardium. We now show that CSD affects integrinmediated NTK signaling, almost completely reversing TACinduced activation down to baseline levels. These observations are consistent with literature demonstrating the ability of caveolin-1 to interact with both receptor tyrosine kinases and NTKs and inhibit their activities. ${ }^{54,55}$

Caveolin-1 has been linked to the inhibition of eNOS expression and activation and NO production by endothelial a

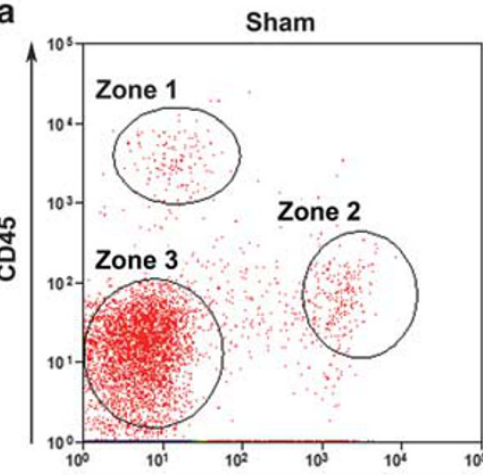

TAC

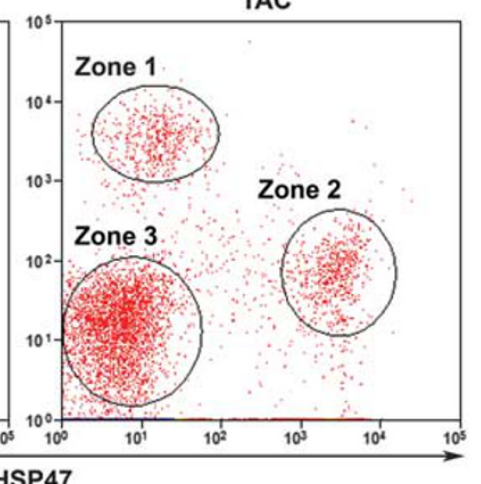

b

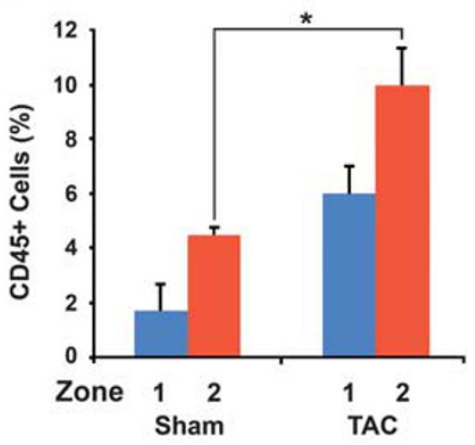

C NIR-B Channel
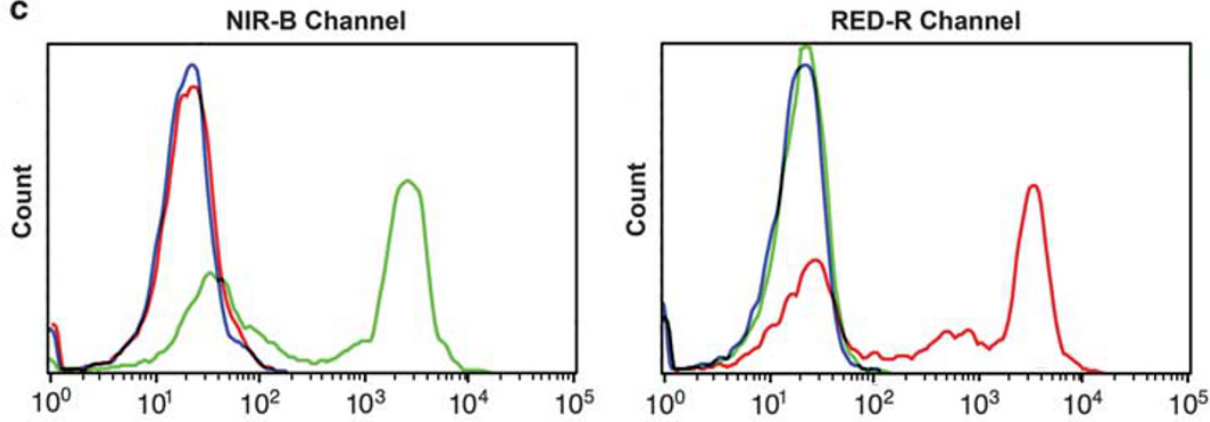

Figure 7 Increased numbers of HSP47+ cells in TAC hearts. Cells were isolated from control (Sham) and TAC mice 2 week after surgery and analyzed by flow cytometry using antibodies against CD45, HSP47, CD11b, CD16, and CD68 (Figure 8). (a) CD45 vs HSP47 scatter plots. Note that there are more cells in TAC mice in Zones 1 and 2 than in Control mice. (b) Quantification of the \% of cells in Zones 1 and 2 in three independent experiments (\% total cells \pm s.e.m.). ${ }^{*} P<0.05$. (c) Cells were labeled with no antibody (blue trace), a PE-Cy7-labeled antibody which is detected in the Near IR-B channel (green trace), or a AlexaFluor647 labeled antibody which is detected in the Red channel (red trace). Note that as expected cells labeled with PE-Cy7 are detected in the Near IR-B channel but not in the Red channel while cells labeled with AlexFluor647 are detected in the Red channel but not in the Near IR-B channel. 
a
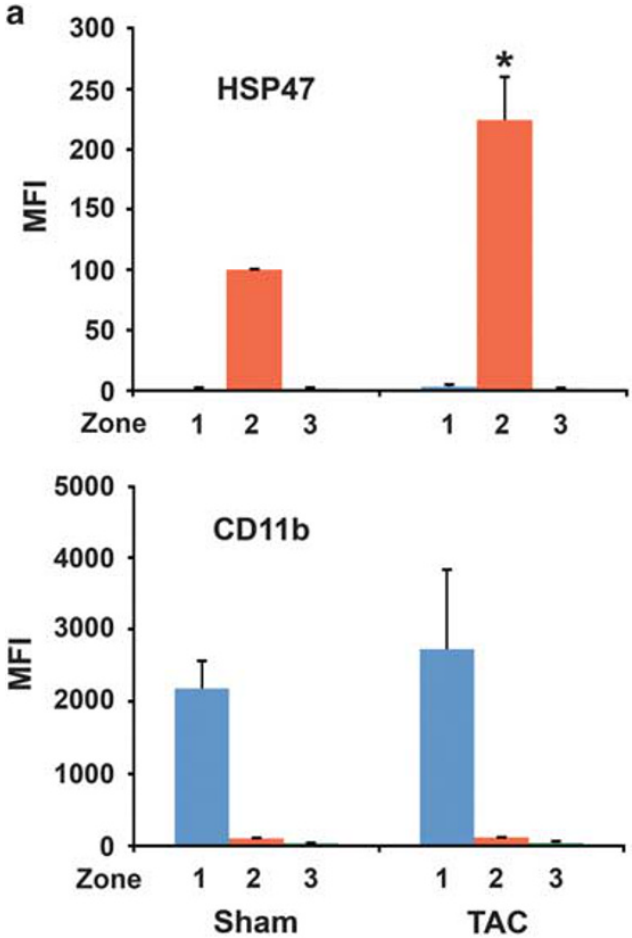
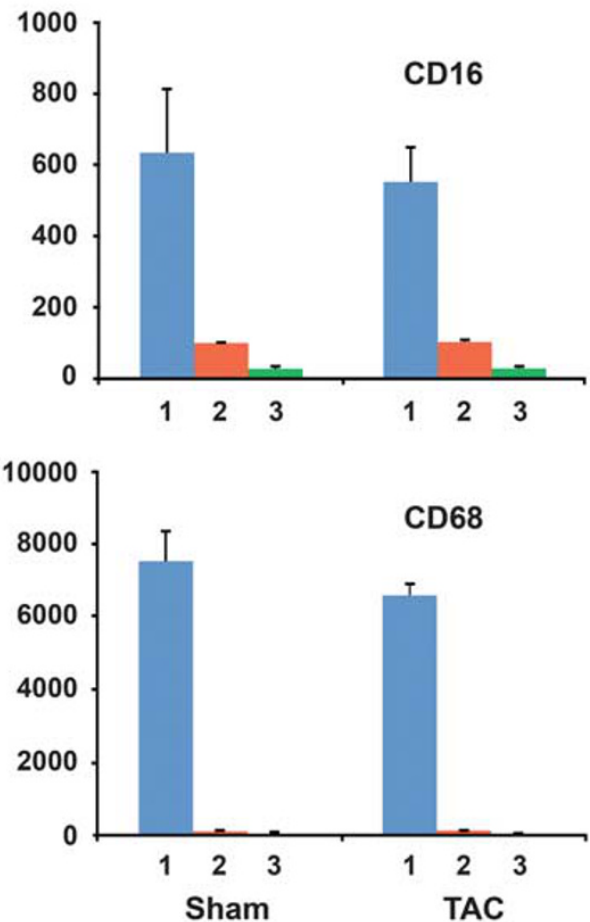

b

\begin{tabular}{|c|c|c|c|}
\hline Zone & 1 & 2 & 3 \\
\hline CD45 & High & Moderate & Low \\
\hline HSP47 & Low & High & Low \\
\hline CD16 & High & Low & Low \\
\hline CD11B & High & Low & Low \\
\hline CD68 & High & Low & Low \\
\hline
\end{tabular}

Figure 8 Analyses of macrophage markers. The experiment is described in the legend to Figure 7. (a) The data shown represent the average from three independent experiments of the mean fluorescence intensity (MFI) ( \pm s.e.m.) for each indicated marker in arbitrary units. The value in Zone 2 was set to 100 arbitrary units. ${ }^{*} P<0.05$ for HSP47 Sham Zone 2 vs TAC Zone 2. For HSP47 Zone 2 vs HSP47 Zones 1 and 3, CD11b Zone 1 vs CD11b Zones 2 and 3, CD16 Zone 1 vs CD16 Zones 2 and 3, and CD68 Zone 1 vs CD68 Zones 2 and 3, P<0.001. (b) Data from Figures 7 and 8a are summarized in tabular form.

cells. ${ }^{20}$ Although NO production has beneficial effects on the cardiovascular system due to causing vasodilation and increased blood flow, excessive NO production can cause detrimental effects in $\mathrm{PO}$ myocardium ${ }^{56}$ by promoting superoxide production..$^{57,58}$ Just as TAC-induced NTK activation that was reversed by CSD, TAC-induced activation of eNOS that was reversed by CSD. The loss of eNOS activity due to CSD could have been expected to increase blood pressure in our experiments; however, we know from the literature that CSD treatment does not alter blood pressure. ${ }^{59,60}$ Therefore, the beneficial effects of CSD are not related to a decrease in blood pressure.

Monocyte-derived cells have been proposed to play roles in the progression of fibrosis both as precursors to the myofibroblasts that overexpress ECM proteins and as precursors to macrophages that overexpress cytokines and chemokines that activate fibroblasts into myofibroblasts and recruit inflammatory cells from the circulation. Whether these populations are entirely distinct is controversial. Cells intermediate in the differentiation of monocytes to myofibroblasts have been referred to as fibrocytes and are recognized by their co-expression of the hematopoietic cell marker CD45 and the mesenchymal cell marker collagen $\mathrm{I}^{61-63}$ (or a surrogate marker for collagen I such as HSP47 (ref. 32). The functions of fibrocytes and macrophages overlap in that both secrete profibrotic cytokines and chemokines $^{32,64,65}$ and in that some cells have been described as collagen-producing macrophages. ${ }^{66} \mathrm{~A}$ specific feature of macrophages is their phagocytic activity. Macrophages also express markers (eg, CD11b, CD16, CD68) which we show are not present on heart $\mathrm{CD} 45^{\text {moderate }} / \mathrm{HSP} 47+$ fibrocytes.

Although more experiments need to be performed, we have never detected HSP47+ cells in the circulation of TAC animals. Therefore, we conclude that HSP47 is expressed at high levels in $\mathrm{CD} 45^{\text {moderate }}$ cells only after they are recruited into the heart. Our other observations on HSP47 add to its 
importance in heart fibrosis. Western blotting, IHC, and RT-PCR studies all demonstrate a major increase in HSP47 levels in TAC hearts that is reversed by CSD. These observations are consistent with the fact that HSP47 has been used successfully as a therapeutic target in rats in which myocardial infarction was induced. ${ }^{67}$

To further determine whether the CD45 ${ }^{\text {moderate }} / \mathrm{HSP} 47+$ cells that we detect in increased numbers with elevated levels of HSP47 in the TAC heart can be considered to be fibroblast precursors or even fibroblasts themselves, we have initiated fibroblast cultures. Indeed, we find by flow cytometry that heart fibroblasts from fibrotic tissue, express CD45, collagen I, and HSP47 (not shown), strongly suggesting that heart fibroblasts can be BM-derived. This conclusion agrees with the work of Entman and colleagues ${ }^{6,9,68-70}$ showing that during ischemic cardiomyopathy and heart failure, BM monocytes recruited into the tissue differentiate into CD45+ mesenchymal cells and contribute to fibrosis and adverse remodeling. This conclusion also agrees with studies $^{10,71-73}$ demonstrating a contribution of hematopoietic cells to mesenchymal cell populations in fibrotic tissue using chimeric mouse models wherein genetically-tagged (eg, EGFP) cells are used to reconstitute the BM of irradiated mice. This conclusion is challenged by investigators who have depended on Cre drivers for lineage specificity and on the failure to stain fibrotic tissues for CD45, 2,3,74 a difficult protein to detect without proper fixation.

In the present study, we have shown in an animal model in which PO results in heart failure with reduced ejection fraction, that CSD has a significant beneficial effect on heart function and morphology. Thus, CSD may potentially be developed as a therapeutic for suppressing cardiac fibrosis and improving ventricular function in patients with $\mathrm{CHF}$ with reduced ejection fraction. Given that a major portion of human heart failure patients exhibit a preserved ejection fraction, it will be interesting in future experiments to use a less restrictive version of TAC surgery or an Angiotensin II infusion model to determine whether CSD may also be a beneficial treatment for heart failure with preserved ejection fraction.

\section{ACKNOWLEDGMENTS}

This work was supported by the College of Medicine Enhancement of Team Science (COMETS) grant to SH and DK and the UNCF/Merck Graduate Science Research Fellowship to DP. We would like to thank Antony Gaspar, PhD, for his helpful suggestions with the RT-PCR experiments and Roger Markwald, PhD, for his many, significant discussions on fibrocytes.

\section{DISCLOSURE/CONFLICT OF INTEREST}

The authors declare no conflict of interest.

1. Moore-Morris T, Guimaraes-Camboa N, Yutzey KE, et al. Cardiac fibroblasts: from development to heart failure. J Mol Med 2015;93: 823-830.

2. Ali SR, Ranjbarvaziri S, Talkhabi M, et al. Developmental heterogeneity of cardiac fibroblasts does not predict pathological proliferation and activation. Circ Res 2014;115:625-635.
3. Moore-Morris T, Guimaraes-Camboa N, Banerjee I, et al. Resident fibroblast lineages mediate pressure overload-induced cardiac fibrosis. J Clin Invest 2014;124:2921-2934.

4. Fan D, Takawale A, Lee J, et al. Cardiac fibroblasts, fibrosis and extracellular matrix remodeling in heart disease. Fibrogenesis Tissue Repair 2012;5:15

5. Krenning G, Zeisberg EM, Kalluri R. The origin of fibroblasts and mechanism of cardiac fibrosis. J Cell Physiol 2010;225:631-637.

6. Crawford JR, Haudek SB, Cieslik KA, et al. Origin of developmental precursors dictates the pathophysiologic role of cardiac fibroblasts. J Cardiovasc Transl Res 2012;5:749-759.

7. Hinz B, Phan SH, Thannickal VJ, et al. Recent developments in myofibroblast biology: paradigms for connective tissue remodeling. Am J Pathol 2012;180:1340-1355.

8. Haudek SB, Cheng J, Du J, et al. Monocytic fibroblast precursors mediate fibrosis in angiotensin-Il-induced cardiac hypertrophy. J Mol Cell Cardiol 2010;49:499-507.

9. Haudek SB, Xia Y, Huebener P, et al. Bone marrow-derived fibroblast precursors mediate ischemic cardiomyopathy in mice. Proc Natl Acad Sci USA 2006;103:18284-18289.

10. Mollmann $\mathrm{H}$, Nef HM, Kostin $\mathrm{S}$, et al. Bone marrow-derived cells contribute to infarct remodelling. Cardiovasc Res 2006;71:661-671.

11. Xu J, Lin SC, Chen J, et al. CCR2 mediates the uptake of bone marrowderived fibroblast precursors in angiotensin II-induced cardiac fibrosis. Am J Physiol Heart Circ Physiol 2011;301:H538-H547.

12. Keeley EC, Mehrad B, Janardhanan R, et al. Elevated circulating fibrocyte levels in patients with hypertensive heart disease. J Hypertens 2012;30:1856-1861.

13. Tourkina E, Gooz P, Pannu J, et al. Opposing effects of protein kinase Calpha and protein kinase Cepsilon on collagen expression by human lung fibroblasts are mediated via MEK/ERK and caveolin-1 signaling. J Biol Chem 2005;280:13879-13887.

14. Wang XM, Zhang Y, Kim HP, et al. Caveolin-1: a critical regulator of lung fibrosis in idiopathic pulmonary fibrosis. J Exp Med 2006;203:2895-2906.

15. Couet J, Li S, Okamoto T, et al. Identification of peptide and protein ligands for the caveolin-scaffolding domain. Implications for the interaction of caveolin with caveolae-associated proteins. J Biol Chem 1997;272:6525-6533.

16. Oka N, Yamamoto $M$, Schwencke $C$, et al. Caveolin interaction with protein kinase $C$. Isoenzyme-dependent regulation of kinase activity by the caveolin scaffolding domain peptide. J Biol Chem 1997;272:33416-33421.

17. Rybin VO, Xu X, Steinberg SF. Activated protein kinase $C$ isoforms target to cardiomyocyte caveolae: stimulation of local protein phosphorylation. Circ Res 1999;84:980-988.

18. Razani $B$, Zhang $X L$, Bitzer $M$, et al. Caveolin-1 regulates transforming growth factor (TGF)-beta/SMAD signaling through an interaction with the TGF-beta type I receptor. J Biol Chem 2001;276:6727-6738.

19. Le Saux CJ, Teeters K, Miyasato SK, et al. Down-regulation of caveolin-1, an inhibitor of transforming growth factor-beta signaling, in acute allergen-induced airway remodeling. J Biol Chem 2008;283:5760-5768.

20. Bernatchez PN, Bauer PM, Yu J, et al. Dissecting the molecular control of endothelial NO synthase by caveolin-1 using cell-permeable peptides. Proc Natl Acad Sci USA 2005;102:761-766.

21. Drab $M$, Verkade $P$, Elger $M$, et al. Loss of caveolae, vascular dysfunction, and pulmonary defects in caveolin-1 gene-disrupted mice. Science 2001;293:2449-2452.

22. Razani B, Engelman JA, Wang XB, et al. Caveolin-1 null mice are viable but show evidence of hyperproliferative and vascular abnormalities. J Biol Chem 2001;276:38121-38138.

23. Cohen AW, Park DS, Woodman SE, et al. Caveolin-1 null mice develop cardiac hypertrophy with hyperactivation of p42/44 MAP kinase in cardiac fibroblasts. Am J Physiol Cell Physiol 2003;284:C457-C474.

24. Del Galdo F, Sotgia F, de Almeida CJ, et al. Decreased expression of caveolin 1 in patients with systemic sclerosis: crucial role in the pathogenesis of tissue fibrosis. Arthritis Rheum 2008;58:2854-2865.

25. Tourkina E, Richard M, Oates J, et al. Caveolin-1 regulates leucocyte behaviour in fibrotic lung disease. Ann Rheum Dis 2010;69:1220-1226.

26. Kasper M, Reimann T, Hempel U, et al. Loss of caveolin expression in type I pneumocytes as an indicator of subcellular alterations during lung fibrogenesis. Histochem Cell Biol 1998;109:41-48.

27. Lee R, Perry B, Heywood J, et al. Caveolin-1 regulates chemokine receptor 5-mediated contribution of bone marrow-derived cells to dermal fibrosis. Front Pharmacol 2014;5:140. 
28. Lee $\mathrm{R}$, Reese $\mathrm{C}$, Bonner $\mathrm{M}$, et al. Bleomycin delivery by osmotic minipump: similarity to human scleroderma interstitial lung disease. Am J Physiol Lung Cell Mol Physiol 2014;306:L736-L748.

29. Tourkina E, Bonner M, Oates J, et al. Altered monocyte and fibrocyte phenotype and function in scleroderma interstitial lung disease: reversal by caveolin-1 scaffolding domain peptide. Fibrogenesis Tissue Repair 2011;4:15.

30. Reese C, Perry B, Heywood J, et al. Caveolin-1 deficiency may predispose African Americans to systemic sclerosis-related interstitial lung disease. Arthritis Rheumatol 2014;66:1909-1919.

31. Miyasato SK, Loeffler J, Shohet R, et al. Caveolin-1 modulates TGFbeta1 signaling in cardiac remodeling. Matrix Biol 2011;30:318-329.

32. Shivshankar P, Halade GV, Calhoun C, et al. Caveolin-1 deletion exacerbates cardiac interstitial fibrosis by promoting M2 macrophage activation in mice after myocardial infarction. J Mol Cell Cardiol 2014;76:84-93.

33. Yi SL, Liu XJ, Zhong JQ, et al. Role of caveolin-1 in atrial fibrillation as an anti-fibrotic signaling molecule in human atrial fibroblasts. PLoS One 2014;9:e85144.

34. Tahir SA, Park S, Thompson TC. Caveolin-1 regulates VEGF-stimulated angiogenic activities in prostate cancer and endothelial cells. Cancer Biol Ther 2009;8:2286-2296.

35. Tahir SA, Yang G, Goltsov AA, et al. Tumor cell-secreted caveolin-1 has proangiogenic activities in prostate cancer. Cancer Res 2008;68: 731-739.

36. Bucci $\mathrm{M}$, Gratton JP, Rudic RD, et al. In vivo delivery of the caveolin-1 scaffolding domain inhibits nitric oxide synthesis and reduces inflammation. Nat Med 2000;6:1362-1367.

37. Lee R, Reese C, Perry B, et al. Enhanced chemokine-receptor expression, function, and signaling in healthy African American and scleroderma-patient monocytes are regulated by caveolin-1. Fibrogenesis Tissue Repair 2015;8:11.

38. Tourkina E, Richard M, Gooz P, et al. Antifibrotic properties of caveolin1 scaffolding domain in vitro and in vivo. Am J Physiol Lung Cell Mol Physiol 2008;294:L843-L861.

39. Balasubramanian S, Quinones L, Kasiganesan $H$, et al. beta3 integrin in cardiac fibroblast is critical for extracellular matrix accumulation during pressure overload hypertrophy in mouse. PLoS One 2012; 7:e45076.

40. Sundararaj K, Pleasant DL, Moschella PC, et al. mTOR complexes repress hypertrophic agonist-stimulated expression of connective tissue growth factor in adult cardiac muscle cells. J Cardiovasc Pharmacol 2016;67:110-120.

41. Johnston RK, Balasubramanian S, Kasiganesan H, et al. Beta3 integrinmediated ubiquitination activates survival signaling during myocardial hypertrophy. FASEB J 2009;23:2759-2771.

42. Balasubramanian S, Pleasant DL, Kasiganesan $\mathrm{H}$, et al. Dasatinib attenuates pressure overload induced cardiac fibrosis in a murine transverse aortic constriction model. PLoS One 2015;10:e0140273.

43. Willey CD, Balasubramanian S, Rodriguez Rosas $M C$, et al. Focal complex formation in adult cardiomyocytes is accompanied by the activation of beta3 integrin and c-Src. J Mol Cell Cardiol 2003;35: 671-683.

44. Huang PL. eNOS, metabolic syndrome and cardiovascular disease. Trends Endocrinol Metab 2009;20:295-302.

45. Pilling D, Roife D, Wang $M$, et al. Reduction of bleomycin-induced pulmonary fibrosis by serum amyloid P. J Immunol 2007;179: 4035-4044.

46. Conrad $\mathrm{CH}$, Brooks WW, Hayes JA, et al. Myocardial fibrosis and stiffness with hypertrophy and heart failure in the spontaneously hypertensive rat. Circulation 1995;91:161-170.

47. Gaasch WH, Zile MR. Left ventricular diastolic dysfunction and diastolic heart failure. Annu Rev Med 2004;55:373-394.

48. Gradman AH, Wilson JT. Hypertension and diastolic heart failure. Curr Cardiol Rep 2009;11:422-429.

49. Weber KT, Anversa P, Armstrong PW, et al. Remodeling and reparation of the cardiovascular system. J Am Coll Cardiol 1992;20:3-16.

50. Zile MR, Baicu CF, Ikonomidis JS, et al. Myocardial stiffness in patients with heart failure and a preserved ejection fraction: contributions of collagen and titin. Circulation 2015;131:1247-1259.

51. Murata T, Lin MI, Huang $\mathrm{Y}$, et al. Reexpression of caveolin-1 in endothelium rescues the vascular, cardiac, and pulmonary defects in global caveolin-1 knockout mice. J Exp Med 2007;204:2373-2382.
52. Fridolfsson $\mathrm{HN}$, Patel $\mathrm{HH}$. Caveolin and caveolae in age associated cardiovascular disease. J Geriatr Cardiol 2013;10:66-74.

53. Jasmin JF, Rengo G, Lymperopoulos A, et al. Caveolin-1 deficiency exacerbates cardiac dysfunction and reduces survival in mice with myocardial infarction. Am J Physiol Heart Circ Physiol 2011;300: H1274-H1281.

54. Li S, Couet J, Lisanti MP. Src tyrosine kinases, Galpha subunits, and $\mathrm{H}$-Ras share a common membrane-anchored scaffolding protein, caveolin. Caveolin binding negatively regulates the auto-activation of Src tyrosine kinases. J Biol Chem 1996;271:29182-29190.

55. Patel $\mathrm{HH}$, Murray $\mathrm{F}$, Insel PA. Caveolae as organizers of pharmacologically relevant signal transduction molecules. Annu Rev Pharmacol Toxicol 2008;48:359-391.

56. van Deel ED, Octavia $Y$, de Boer $M$, et al. Normal and high eNOS levels are detrimental in both mild and severe cardiac pressure-overload. J Mol Cell Cardiol 2015;88:145-154.

57. Beckman JS, Beckman TW, Chen J, et al. Apparent hydroxyl radical production by peroxynitrite: implications for endothelial injury from nitric oxide and superoxide. Proc Natl Acad Sci USA 1990;87: 1620-1624.

58. Poderoso JJ. The formation of peroxynitrite in the applied physiology of mitochondrial nitric oxide. Arch Biochem Biophys 2009;484: 214-220.

59. Desjardins F, Lobysheva I, Pelat M, et al. Control of blood pressure variability in caveolin-1-deficient mice: role of nitric oxide identified in vivo through spectral analysis. Cardiovasc Res 2008;79:527-536.

60. Gratton JP, Lin MI, Yu J, et al. Selective inhibition of tumor microvascular permeability by cavtratin blocks tumor progression in mice. Cancer Cell 2003;4:31-39.

61. Herzog EL, Bucala R. Fibrocytes in health and disease. Exp Hematol 2010;38:548-556

62. Keeley EC, Mehrad B, Strieter RM. The role of circulating mesenchymal progenitor cells (fibrocytes) in the pathogenesis of fibrotic disorders. Thromb Haemost 2009;101:613-618.

63. Pilling D, Fan T, Huang D, et al. Identification of markers that distinguish monocyte-derived fibrocytes from monocytes, macrophages, and fibroblasts. PLoS One 2009;4:e7475.

64. Chesney J, Metz C, Stavitsky AB, et al. Regulated production of type I collagen and inflammatory cytokines by peripheral blood fibrocytes. J Immunol 1998;160:419-425.

65. Hartlapp I, Abe R, Saeed RW, et al. Fibrocytes induce an angiogenic phenotype in cultured endothelial cells and promote angiogenesis in vivo. FASEB J 2001;15:2215-2224.

66. Mathai SK, Gulati M, Peng X, et al. Circulating monocytes from systemic sclerosis patients with interstitial lung disease show an enhanced profibrotic phenotype. Lab Invest 2010;90:812-823.

67. Hagiwara S, Iwasaka H, Shingu C, et al. Heat shock protein 47 (HSP47) antisense oligonucleotides reduce cardiac remodeling and improve cardiac function in a rat model of myocardial infarction. Thorac Cardiovasc Surg 2011;59:386-392.

68. Cieslik KA, Trial J, Crawford JR, et al. Adverse fibrosis in the aging heart depends on signaling between myeloid and mesenchymal cells; role of inflammatory fibroblasts. J Mol Cell Cardiol 2014;70:56-63.

69. Cieslik KA, Trial J, Entman ML. Mesenchymal stem cell-derived inflammatory fibroblasts promote monocyte transition into myeloid fibroblasts via an IL-6-dependent mechanism in the aging mouse heart. FASEB J 2015;29:3160-3170.

70. Haudek SB, Trial J, Xia Y, et al. Fc receptor engagement mediates differentiation of cardiac fibroblast precursor cells. Proc Natl Acad Sci USA 2008;105:10179-10184.

71. Ruiz-Villalba A, Simon AM, Pogontke C, et al. Interacting resident epicardium-derived fibroblasts and recruited bone marrow cells form myocardial infarction scar. J Am Coll Cardiol 2015;65:2057-2066.

72. van Amerongen MJ, Bou-Gharios G, Popa E, et al. Bone marrow-derived myofibroblasts contribute functionally to scar formation after myocardial infarction. J Pathol 2008;214:377-386.

73. Visconti RP, Markwald RR. Recruitment of new cells into the postnatal heart: potential modification of phenotype by periostin. Ann NY Acad Sci 2006;1080:19-33.

74. Moore-Morris $\mathrm{T}$, Cattaneo $\mathrm{P}$, Puceat $\mathrm{M}$, et al. Origins of cardiac fibroblasts. J Mol Cell Cardiol 2016;91:1-5.

75. Reese $C$, Lee $R$, Bonner $M$, et al. Fibrocytes in the fibrotic lung: altered phenotype detected by flow cytometry. Front Pharmacol 2014;5:141. 